\title{
Bi-plane breast augmentation: a case series supporting its use and benefits
}

\author{
Matthew Stodell, Gordon McArthur, Mathew James \\ Deapartment of Plastic, Hand and Reconstructive Surgery. St Thomas' Hospital, Guys and St. Thomas' NHS Trust, London, SE1 7EH, UK. \\ Address for correspondence: Dr. Mathew James, St Thomas' Hospital, Guys and St. Thomas' NHS Trust, London, SE1 7EH, UK. \\ E-mail: mattjames@doctors.net.uk
}

\begin{abstract}
Aim: Breast augmentation has traditionally been performed in either the subglandular or submuscular plane. Dual plane augmentation has been described before and captures the advantages of both of these techniques but reduces the trade-offs. The biplane muscle splitting technique adopts the similar advantages seen with the dual plane method without the need for extensive costal muscle fibre release at the infra-mammary fold. Methods: Thirty-five patients underwent bilateral breast augmentation using the biplanar technique from November 2007 to December 2008. All operations were performed by the senior author and followed up prospectively. Results: Follow up ranged from 9 months to 21 months. All of the patients achieved precise and reliable implant placement with no revisions or patient dissatisfaction. There have been no cases of implant misplacement/migration; synmastia, dynamic breast deformity, capsular contracture or infections. A single case of unilateral haematoma occurred early in the series. Conclusion: Our operative cases and early follow-up supports the use of this novel biplanar technique for breast augmentation. It optimizes the advantages of subglandular and submuscular breast augmentation with simpler dissection and less complications than other submuscular techniques. It can be used in a wide variety of breast types with predictable results.
\end{abstract}

Key words:

Biplane; dual-plane; breast augmentation; submuscular implants; muscle splitting augmentation

\section{INTRODUCTION}

The use of a dual plane for breast augmentation is not a new concept. ${ }^{[1]}$ Its use in primary breast augmentation is becoming more popular and can be performed through various different approaches. ${ }^{[2]}$ Indeed it is becoming a recognised method for the correction of established capsular contracture in secondary breast augmentation. ${ }^{[3]}$ The concept of the biplane muscle splitting technique was only introduced by Khan ${ }^{[4]}$ in 2007. It differs from the aforementioned dual plane technique as the implant is positioned both in front of and behind pectoral is major simultaneously without the need of muscle release. Here

\begin{tabular}{|l|l|}
\multicolumn{2}{|c|}{ Access this article online } \\
\hline Quick Response Code: & Website: \\
\hline & http://par.oaepublish.com/ \\
\cline { 2 - 3 } & DOI: \\
\hline
\end{tabular}

we present a case series of women who have all undergone bilateral breast augmentation using the same technique that Khan describes. This study supports and further reinforces the benefits and advantages of this novel technique.

\section{METHODS}

Thirty-five patients underwent bilateral breast augmentation using the biplanar technique from November 2007 to December 2008. All operations were performed by the

This is an open access article distributed under the terms of the Creative Commons Attribution-NonCommercial-ShareAlike 3.0 License, which allows others to remix, tweak and build upon the work non-commercially, as long as the author is credited and the new creations are licensed under the identical terms.

For reprints contact: service@oaepublish.com

How to cite this article: Stodell M, McArthur G, James M. Bi-plane breast augmentation: a case series supporting its use and benefits. Plast Aesthet Res 2016;3:17-20.

Received: 29-04-2015; Accepted: $26-10-2015$ 
senior author and followed up prospectively.

Surgical technique: Midline is drawn from sternal notch to xiphisternum as a reference point and inframammary incision is marked preoperatively with patient in standing position.

The procedure is performed in general anaesthetic with muscle relaxation with the patient in a supine position with their arms abducted. The marked mid-line is used for reference and future breast pocket is marked. Approximate positions of the origins of pectoralis major are marked and a line, extending between the junction of middle and lower third of sternum and anterior axillary fold is drawn, roughly level with the lower border of the areola. The line represents the level where the muscle splitting incision takes place. The infra-mammary incisions are made approximately $5 \mathrm{~cm}$ in length and positioned laterally to conceal them in the inframammary fold [Figure 1].

Dissection first takes place in the sub-glandular plane using cutting diathermy and continues superiorly up to the level of the nipple-areola complex superiorly and between the junction of middle and lower third of sternum medially going up and laterally to the anterior axillary fold [Figure 2].

The subpectoral pocket is accessed by separating the muscle fibres close to their origin at the previously marked level and the pocket is created by blunt dissection [Figure 3]. The medial two-thirds of pectoralis major are split in line with the muscle fibres maintaining the lateral portion of the muscle, which locks the implant and helps prevent lateral or

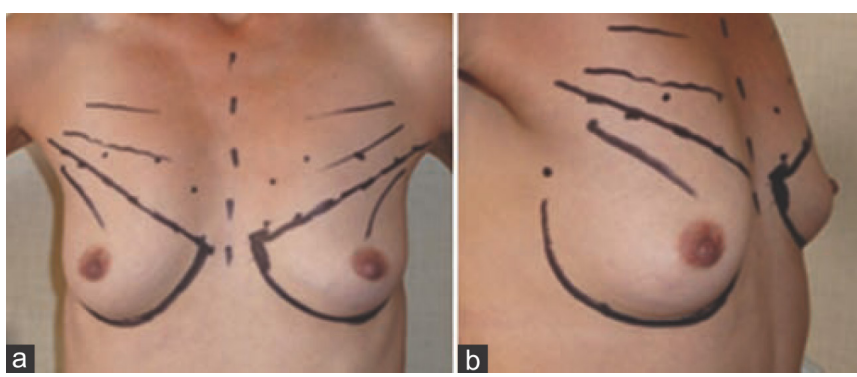

Figure 1: Preoperative skin markings

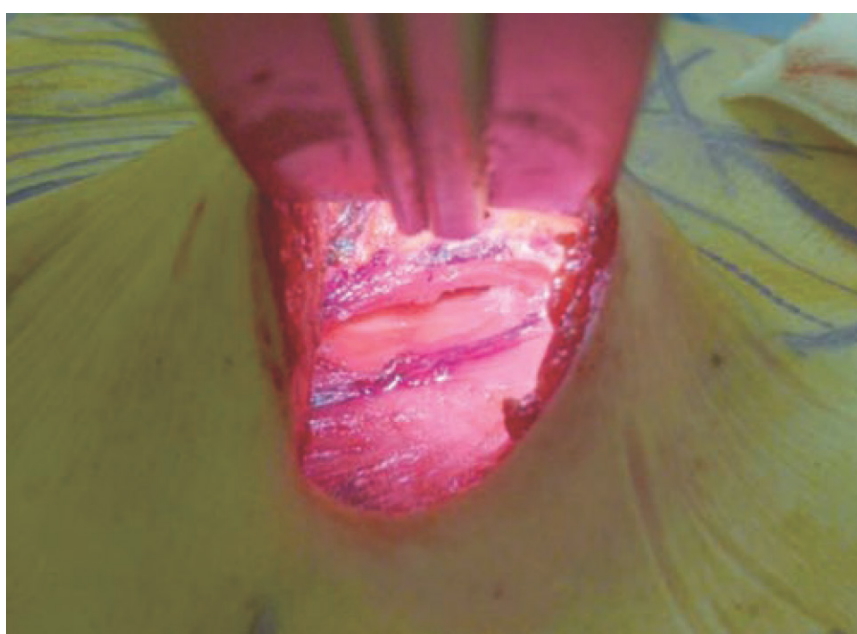

Figure 3: The muscle-splitting incision is made and access to the subpectoral pocket is gained upward migration. The implant is inserted with the superior portion in the subpectoral plane and the incision closed occasionally with the placement of a drain.

\section{RESULTS}

Follow up ranged from 9 months to 21 months. All of the patients achieved precise and reliable implant placement with no revisions or patient dissatisfaction. There have been no cases of implant misplacement/migration; synmastia, dynamic breast deformity, capsular contracture or infections. A single case of unilateral haematoma occurred early in the series.

\section{DISCUSSION}

The use of a dual plane for breast augmentation has been well documented in the past by Tebbetts. ${ }^{[1]}$ Dual plane is an extension of partial sub muscular technique where muscle release is performed depending on the presence of the skin envelope. The bi-plane method, or muscle-splitting technique, has been described by Khan in 2007. ${ }^{[4]}$ The submuscular positioning of the implant offers less capsular contracture rate. ${ }^{[5]}$ This method involves splitting the pectoralis major

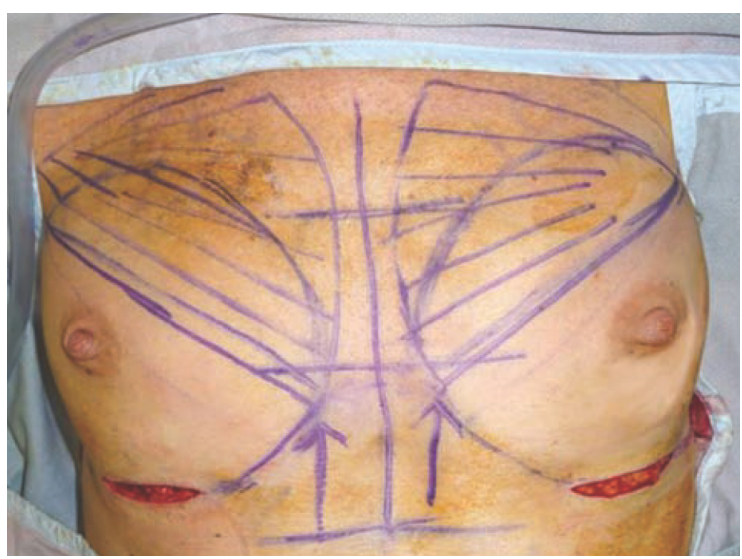

Figure 2: Arrows point to the level where the muscle-splitting incision is made and lower unmarked area represents the extent of subglandular pocket

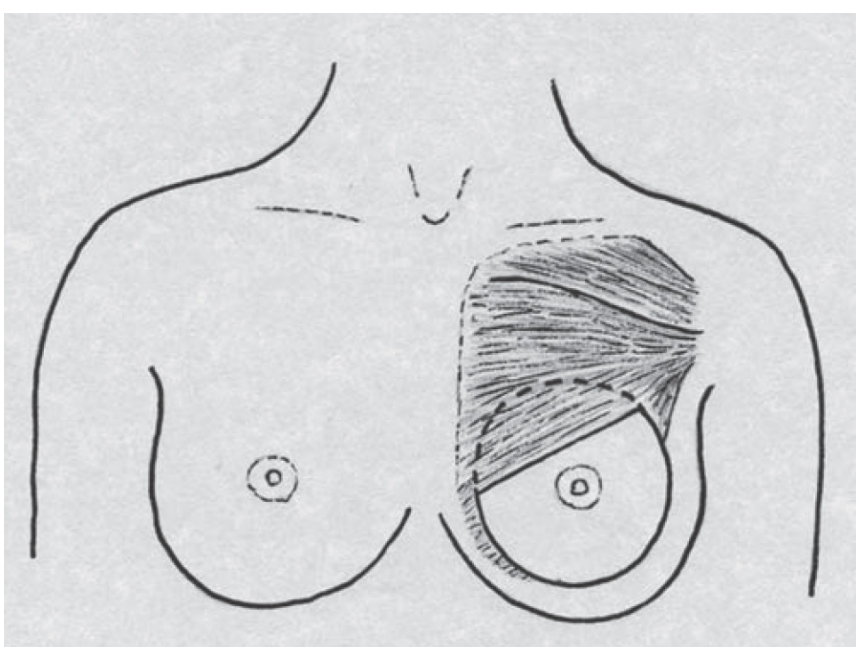

Figure 4: Anterior view showing position of the implant with the inferior portion anterior to pectoralis major. The subpectoral plane is accessed by splitting the muscle in the line of its fibres, lateral conjoined pectoralis prevents lateral and superior displacements 


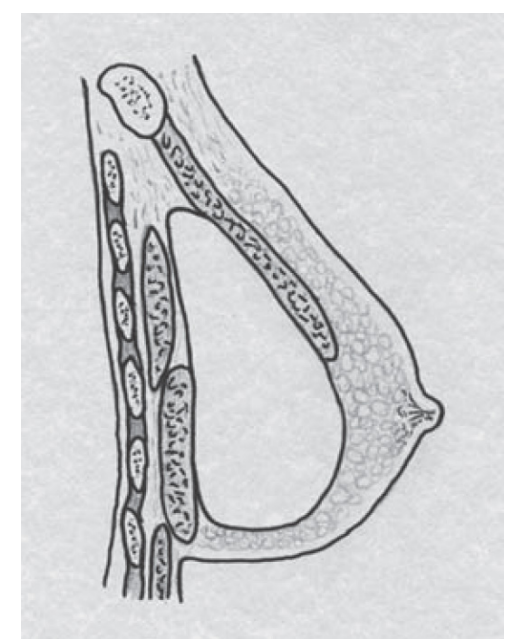

Figure 5: Sagittal view showing the prosthesis in-situ. Anterior to the implant is the superior portion of pectoralis major. Posterior to the implant lies pectoralis minor and the inferior portion of pectoralis major

in the line of its fibres to gain access to the submuscular plane as opposed to division of the pectoralis major along the infra-mammary fold [Figure 4]. The technique has been described for primary ${ }^{[6-9]}$ and secondary procedures. ${ }^{[10-12]}$ The technique not only reduces the dynamic deformity due to absence of muscle release but also has been described to correct dynamic deformity associated with partial sub muscular or dual plane augmentation mammoplasty. ${ }^{[13,14]}$ In Muscle splitting Biplane, the pectoralis lies behind and in front of the implant at the same time and without the muscle release [Figure 5].

As Tebbetts has described, the use of a dual plane technique reduces the trade-offs commonly seen in subglandular or subpectoral implant placement. With subglandular placements there is an increased risk of a visible or palpable edge of the prosthesis, especially in the upper pole where there may be insufficient soft tissue coverage. There is also possibly an increased risk of capsular contracture leading to pain or breast deformity.

Although, historically, subpectoral breast implants have been reported as having lower incidences of capsular contracture ${ }^{[5]}$ the technique is not without its disadvantages. There is a higher incidence of implant migration, dynamic breast deformity and less precise control of breast shape. ${ }^{[1]}$

Use of the biplane technique compared with subglandular placement affords more adequate soft tissue coverage in the upper pole with a less stark transition between skin and implant. A long term review of a large study has shown a 6-7 fold reduction in the over rate of revision surgeries, when Muscle Splitting Biplane augmentation was compared with conventional sub glandular and partial submuscular augmentation mammoplasty. ${ }^{[15 \mid}$ The submuscular positioning of implants in biplane also offers reduces incidence of capsular contracture..$^{[5]}$ In our series there have been no cases of capsular contracture so far, however, a larger series with well monitored long term follow up will be required for an actual rate of capsular contracture.

The muscular attachment and portion of pectoralis major
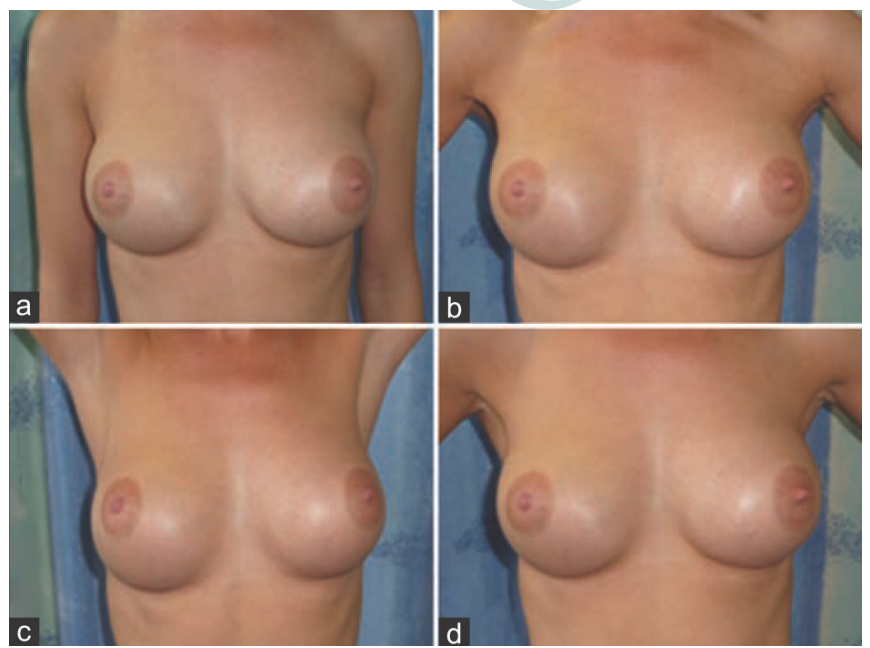

Figure 6: Postoperative anterior views of a young woman in (a) relaxed position; (b) hands on hips; (c) arms fully abducted; and (d) forced contraction of pectoralis showing no dynamic muscle deformity

used to cover the superior pole of the implant has not been shown to cause any significant muscle contraction associated deformities as may be the case with total sub muscular or dual plane techniques [Figure 6]. In comparison with partial sub muscular or dual plane implant positioning, where the muscle is released from the sternocostal margin, the biplane technique has the added advantage of less incidences of dynamic breast deformity due to absence of the release of the muscle. ${ }^{[4,13,14]}$ The muscle splitting technique does not require division of any of these fibres so that they are still available for functional use. The communication between the submuscular and sub glandular sections of the pocket allows one unit feel of the breast. The sub glandular position of the implant in the lower pole also allows a more natural and three-dimensional results with the implant covered by the muscle in the ever-changing upper part of the breast.

Intact sternal origin of the pectoralis muscle fibres acts as a fence preventing the implant pockets join over the sternum, thus, eliminating the risk of synmastia. When sternal margins of pectoralis are divided in conventional or dual plane pockets, the two pockets may communicate over the sternum resulting in synmastia. Subglandular positioning of implant with medial quadrant undermining may result in similar complication. The correction of sub glandular synmastia can be corrected by simply converting the pocket in to muscle splitting biplane. ${ }^{[12]}$ To date there have been no cases of synmastia and all of the patients have had an aesthetically pleasing cleavage.

As the muscle-splitting technique only divides the medial two-thirds of pectoralis major, this maintains the lateral portion of pectoralis major. The inferior retro-prosthetic portion conjoins with the superior pre-prosthetic portion of pectoralis major to locks the lateral part of the implant and helps prevent superior and lateral displacement [Figure 4]. There have not been any reported cases of implant displacement or migration in our series.

In comparison to submuscular implant placement, the biplane technique affords the same adequacy of soft tissue cover in the superior pole, but in addition better fill and 
projection in the lower pole. This is especially true in thin women, patients with constricted lower poles or excessive skin envelopes. Conventional submuscular positioning of implants in such patients can lead to a double-bubble deformity. There have been no identifiable cases of this complication in our series. The biplane technique can be used in cases of grade I and II ptosis with satisfactory lower pole fill and projection. The senior author has not used this technique in more severe cases of ptosis.

In conclusion, our operative cases and early follow-up supports the use of this novel biplanar technique for breast augmentation. It optimizes the advantages of subglandular and submuscular breast augmentation with simpler dissection and less complications than other submuscular techniques. It can be used in a wide variety of breast types with predictable results.

\section{Acknowledgements}

Umar D. Khan for introducing the concept of the biplane muscle-splitting technique.

\section{Financial support and sponsorship} Nil.

\section{Conflicts of interest}

There are no conflicts of interest.

\section{REFERENCES}

I. Tebbetts JB. Dual plane breast augmentation: optimizing implant-softtissue relationships in a wide range of breast types. Plast Reconstr Surg 200।; |07:| 255-72.

2. Luan J, Mu D, Mu L. Transaxillary dual-plane augmentation mammaplasty: experience with 98 breasts. J Plast Reconstr Aesthet Surg 2009;62: 1459-63.
3. Spear SL, Carter ME, Ganz JC. The correction of capsular contracture by conversion to "dual-plane" positioning: technique and outcomes. Plast Reconstr Surg 2003; I 12:456-66.

4. Khan UD. Muscle-splitting breast augmentation: a new pocket in a different plane. Aesth Plast Surg 2007;31:553-8.

5. Biggs TM,Yarish RS.Augmentation mammaplasty: a comparative analysis. Plast Reconstr Surg 1990;85:368-72.

6. Khan UD. Vertical scar mastopexy with cat's tail extension for prevention of skin redundancy: an experience with 17 consecutive cases following mastopexy and mastopexy with breast augmentation. Aesthetic Plast Surg 20I2;36:303-7.

7. Khan UD.Augmentation mastopexy in muscle-splitting biplane: outcome of first 44 consecutive cases of mastopexies in a new pocket. Aesth Plast Surg 2010;34:3|3-2I.

8. Khan U D. Multiplane technique for simultaneous submuscular breast augmentation and internal glandulopexy using inframammary crease incision in selected patients with early ptosis. Eur J Plast Surg 20I0;34:337-43.

9. Lang Stumpfle R, Figueras Pereira-Lima L, Alves Valiati A, da Silva Mazzini G. Transaxillary muscle-Splitting breast augmentation: experience with 160 Cases. Aesth Plast Surg 2012;36:343-8.

10. Khan UD. Combining muscle-splitting biplane with multilayer capsulorraphy for the correction of bottoming down following subglandular augmentation Eur J Plast Surg 2010;33:259-69.

I I. Khan UD. Subglandular to Muscle Splitting Biplane Conversion for Revision Augmentation Mammoplasty. In: Mugea TT, Schifmann MA, editors. Aesthetic Surgery of the Breast. Ist ed. Berlin: Springer; 2015. p. 535-4I.

12. Khan UD. Correction of acquired synmastia with of with muscle-splitting biplane implant replacement. Aesth Plast Surg 2009;33:605-10.

13. Khan UD. Dynamic breasts: a common complication following partial submuscular augmentation and its correction using muscle-splitting biplane technique. Aesth Plast Surg 2009;33:353-60.

14. Khan UD. High transverse capsuloplasty for the correction of malpositioned implants following augmentation mammoplasty in partial submuscular plane. Aesth Plast Surg 2012;36:590-9.

15. Khan UD. Muscle-splitting, subglandular and partial submuscular augmentation mammoplasties: a 12-year retrospective analysis of 2026 primary cases. Aesth Plast Surg 2013;37:290-302. 